\section{The influence of Information Management Capability on Companies' Sustainable Competitive Advantage: A Multiple-Case Study of Brazilian Market-Leading Companies}

\author{
Antonio Carlos Gastaud Maçada ${ }^{\mathbf{1}}$ \\ ${ }^{1}$ UFRGS, EA, PPGA, Porto Alegre, Brazil \\ Rafael Alfonso Brinkhues ${ }^{2}$ \\ IFRS, Campus Viamão, Viamão, Brazil \\ José Carlos da Silva Freitas Jr. ${ }^{3}$ \\ ${ }^{3}$ Unisinos, Escola de Gestão e Negócios, São Leopoldo, Brazil
}

\begin{abstract}
Purpose - The aim of this study is to assess the influence of Information Management Capability (IMC) on Companies' Sustainable Competitive Advantage (SCA) based on the qualitative approach.

Design/methodology/approach - This study presents results of a multiple-case study carried out in three leading companies in their sector in Brazil (a credit union, a fashion retailer, and a furniture manufacturer).

Findings - The results point towards a series of connections between Information System capacities (information management and integration) and organizational capacities (flexibility, reconfigurations, and agility), which were observed through content analysis applied to the inter-occurrence of intermediate categories of these capacities.

Originality/value - The strategic impact of information technology resources and capacities remains a source of controversy in the literature. This study contributes to the literature on Information Systems Management and Sustainable Competitive Advantage (SCA). These are influenced by resources and abilities related to information rather than just technological resources.
\end{abstract}

Keywords - Information Management Capability; Organizational Capabilities; Dynamic Capabilities; Sustainable Competitive Advantages.
Received on:

12/04/2018

Approved on:

08/30/2019

Responsible Editor:

Prof. Dr. João Mauricio Gama

Boaventura

Evaluation process:

Double Blind Review

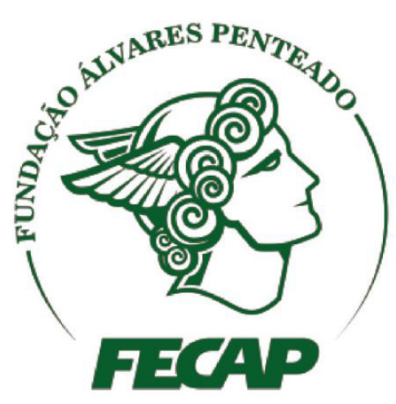

Revista Brasileira de Gestáo de Negócios 


\section{Introduction}

The strategic impact of Information Technology (IT) resources and their influence on organizations' performance remain controversial in the literature on Information Systems (IS) (Chae, Koh, \& Prybutok, 2014; Luse \& Mennecke, 2014; Sabherwal \& Jeyaraj, 2015). Digital technologies mean a new data flow, such as Big Data, which needs to be explored and managed by organizations in order to use it to gain strategic value (Chen, Chiang, \& Storey, 2012; Davenport, Barth, \& Bean, 2012; Grover, Chiang, Liang, \& Zhang, 2018; McAfee, Brynjolfsson, Davenport, Patil, \& Barton, 2012). Developing organizational skills to deal with changes deriving from digital technologies is a competitive need for companies' survival (Bharadwaj, El Sawy, Pavlou, \& Venkatraman, 2013).

The aim of this study is to investigate Information Management Capability (IMC) and its influence as a source of Sustainable Competitive Advantages (SCA) for companies. The combination of better results and efficiency is a consequence of high-quality decision-making, which is made easier by better Information Management Capability (Shamim, Zeng, Shariq, \& Khan, 2018). Studies have shown that IMC has a positive impact on companies' performance (Carmichael, Palacios-Marques, \& Gil-Pechuan, 2011; Mithas, Ramasubbu, \& Sambamurthy, 2011); this impact can be direct (Carmichael et al., 2011) or mediated by other organizational skills (Ali \& Khan, 2019; Levallet \& Chan, 2018; Mithas et al., 2011). Information Management Capability can be understood as a set of company skills that support information infrastructure, architecture, and access, as well as its distribution, which enables organizational adjustments in response to changes imposed by internal and external environments. This construct must also be taken into consideration within the Big Data and Analytics contexts (Ali \& Khan, 2019; Brinkhues, Freitas, \& Maçada, 2015; Maçada, Brinkhues, \& Freitas, 2015) because it would indicate the relationship between these skills and the company's strategic performance (Mikalef, Pappas, Krogstie, \& Giannakos, 2018). “The strategic IS research field is a rich source of evidence that can be used to illustrate resource complementarity issues" (Wade \& Hulland, 2004, p. 123). Thus, IMC is expected to complement other company capabilities in order to increase value within this context. The aim is to answer to the following research question: How can Information Management Capability influence companies' competitive advantages?

This article presents a multiple case study carried out on three market organizations that are leaders in their sectors due to intense information use, namely: a financial institution, a currency exchange group, and a big furniture manufacturer. These cases are relevant because we need to assess stable organizations that are in a favorable position in their sectors. This must be done in order to observe SCA, and to assess the relevance of intense information use to investigate the influence of data management. The data analysis of each case study allowed for an assessment of the propositions of the adopted research model and identification of the patterns that contribute to the pathways through which IMC influenced SCA.

We show how Sustainable Competitive Advantages (SCA) are influenced by resources and skills related to information, rather than just by technological resources. The aim of this research is to provide contributions to the literature by describing the link between IMC and the organizational capabilities identified, mainly by highlighting their role in the exploitation of the strategic values of information resources by companies. Besides, if one takes into account that $85 \%$ of organizations cannot take these new data for granted (Gartner, 2016), the results in the current study may point out how professionals can guide investments to improve company capabilities in order to accomplish better performance within this strategic context.

The first part of the article describes the literature review. It starts by introducing the theoretical perspectives on competitive advantages and goes on to review the evolution of the IMC construct. The research model development is introduced in chapter three. Chapter four describes the methodological procedures applied to the case study. Finally, the results analysis is addressed in chapter five, which ends with the final considerations about the research.

\section{Literature Review}

The literature review was divided into two parts: the main perspectives on competitive advantages and the evolution of IMC. 


\section{I Theoretical perspectives on competitive advantages}

The potential for competitive advantages of IS is best explained and broadly assessed through IS use and through management features in organizations, rather than just through the control of tangible assets (Wade \& Hulland, 2004). According to the Resource Based View (RBV), companies are heterogeneous in their composition and in the use of their resources and capabilities, even when they belong to the same industrial sector (Barney, 1991). A company is said to have competitive advantages when it implements strategies to create value that are not simultaneously being implemented by any other current or potential competitor. A company is said to have SCA "when other companies cannot copy the benefits from these strategies" (Barney, 1991, p. 102). Mata, Fuerst, and Barney (1995) highlight that the focus of IT-based SCA should not lie in IT itself, but in the process to organize and manage IT in the company. Management capability opens up room for discussions and propositions concerning IMC as a source of SCA.

The Dynamic Capability approach (Teece, Pisano, \& Shuen, 1997) is adopted to help better understand strategic changes (Helfat \& Peteraf, 2009) that involve the RBV to the extent that they take into consideration the need to have additional attributes to create competitive advantages within a dynamic environment. This theoretical perspective involves company skills to respond to changes in the environment. Teece et al. (1997, p. 516) define Dynamic Capability as "companies' skills to integrate, build, and reconfigure internal and external competences to quickly respond to changes in the environment." Thus, the perspective of Dynamic Capability as an extension of the RBV is the main theoretical basis for the present research.

\subsection{Information Management Capability}

According to Marchand, Kettinger, and Rollins (2000), studies on information management have been developed by many researchers since the 1950s. They have gone through many stages, starting with IRM (Information Resource Management), subsequently focusing on information lifespan, and finally reaching the IO (Information Orientation) proposition. Information Orientation argued that, separately, the positive impact of IT, information management, and human resources was not observed by managers. However, their benefits would be greatly observed if there was some sort of guidance to integrate actions from these three fields.

Based on the IO, Mithas et al. (2011) provided a definition of IMC. They used a huge database of secondary data and concluded that three management capabilities (clients, performance, and processes) mediate the positive influence of IMC on company performance. This concept is based on three dimensions: (a) the ability to provide data and information to users, at appropriate accuracy, punctuality, safety, and confidentiality levels; (b) the ability to provide connectivity and universal access with adequate range and scale; and (c) the ability to adjust the infrastructure to the needs and emerging directions of the market.

The IMC concept proposed by Carmichael et al. (2011, p. 1617) states that it consists of "co-specific and complementary assets that point towards organizations' ability to understand and use technological, human, and organizational resources that are needed to manage either internal or external information." Their research showed that IMCs have a direct effect on company performance.

Based on these concepts in the literature, it was possible to perceive an existing gap in previous IMC concepts. These old concepts do not address the expected role of this capability in the new informational context and they were not consistent with the theoretical perspectives on capability strategies, the RBV (Carmichael et al. 2011), and Dynamic Capability (Teece et al., 1997). Therefore, the concept of IMC was expanded to cover a set of company skills to access data and information from internal and external environments, to map and distribute this information so it is processed, and to allow for organizational adjustments focused on responding to market needs and directions.

Brinkhues et al. (2015) identified four IMC dimensions in the literature, namely: access to information, information architecture, information distribution, and information infrastructure. They assessed these dimensions through card sorting conducted with 10 IT managers.

\section{Model Development and Research Propositions}

A search in the IS literature was carried out to identify constructs related to IMC in order to achieve SCA - the search was performed among research that has used the Dynamic Capability theory. With the aim of following the guidelines for a systematic literature 
review (Cochrane, 2018), we looked for results in a set of eight journals classified as the main ones in the IS field by the Senior Scholars Consortium of the AIS (Association for Information Systems), namely: European Journal of Information Systems; Information Systems Journal; Information Systems Research; Journal of AIS; Journal of Information Technology; Journal of MIS; Journal of Strategic Information Systems; and MIS Quarterly. The limitation to publications in these journals assured the quality and validity of the study and limited the search to the IS field, which was the focus of the literature review. In total, 54 articles were selected based on this limitation.

The analysis of these publications showed that IT/IS resources and capabilities have a positive impact on companies' financial performance and capabilities. The constructs IS Integration Capability, Flexibility, Reconfiguration Capability, and Agility are seen as company skills that will likely mediate the influence of IMC on SCA.

\section{I IMC and IS Integration Capability}

As mentioned above, IMC must relate to other organizational capabilities to become a source of competitive advantages and to meet sustainability requirements. Herein, integration capability concerns IS integration; it is structural for the management of internal and external resources (Rai \& Tang, 2010). Based on the context of the current research, these resources involve the flow of information generated by other digital technologies.

In order to explore the opportunity to create strategic value, some authors have presented organizational capabilities to be developed for such purposes. The integration of resources and processes was identified as one of these capabilities (Demirkan \& Delen, 2013).

According to Carmichael et al. (2011) and Mithas et al. (2011), besides managing income and captured information, IMC skills also include access to and distribution of information. Thus, IMC is expected to affect IS Integration Capability, as will be investigated based on the first proposition of this research:

P1a - Higher IMC levels are associated with companies' IS Integration Capability.

IS Integration Capability has been assessed based on inter-organizational contexts such as supply chain management (e.g. Rai, Patnayakuni, \& Seth, 2006) and mergers and acquisitions (e.g. Tanriverdi \& Uysal, 2011). However, recently, given the complexity of companies' internal systems and the increase in the number of information sources, some studies have focused on internal IS integration (e.g. Kettinger, Zhang, \& Chang, 2013; Roberts \& Grover, 2012), giving rise to proposition 1 b. $\mathrm{P} 1 \mathrm{~b}$ - Higher IS Integration Capability levels are related to higher IMC levels.

\subsection{IMC and Flexibility}

Adapting means being flexible. Flexibility in response to changes is a factor of IS success (Lee \& Xia, 2005). According to Rai and Tang (2010), IS Integration Capability becomes part of Flexibility through mutual adjustments. There are indications that IS Integration Capability can have a positive influence on companies' adaptations based on the context assessed; this affects the investigation addressed in the second proposition.

Adaptation is also found in IMC definitions when it comes to the need to achieve an adequate infrastructure in order to respond to market demands and directions (Mithas et al. 2011). Thus, the complementary effect between IS Integration Capability and IMC will also influence companies' adaptation capability. This process leads to proposition 2 .

P2 - Higher IMC levels are related to higher organizational flexibility levels.

\subsection{IMC and Reconfiguration Capability}

Butler and Murphy (2008) described integration as the dynamic capability to contribute to resource transformations. Therefore, integration plays a key role in reconfigurations. The capability to reconfigure resources to implement a new configuration, which would correspond to changes in the environment, was supported by Wei and Wang (2010). These authors understand reconfiguration as the dynamic capability to generate competitive advantages in an environment undergoing changes.

Thus, taking into account the new informational context, which demands new resource reconfigurations and organizational processes to be extrapolated, one can observe the relevance of integrating such resources to achieve this reconfiguration. Therefore, the aim with the third proposition was to investigate the influence of IS Integration Capability on companies' Reconfiguration Capability.

On the other hand, IMC also seeks to be a skill to reconfigure information infrastructure itself in order to understand changes in the environment (Mithas et al. 
2011). The theoretical propositions are also based on assumptions about Dynamic Capability. This involves companies' skills in integrating and reconfiguring internal and external competences, with the aim of responding to changes in the environment (Teece et al. 1997). The influence of IMC on Reconfigurations Capability (RC) must be investigated, giving rise to the third proposition: P3 - Higher IMC levels are related to higher Reconfiguration Capability levels.

\subsection{Flexibility and Agility}

The context underlying this study also requires organizational flexibility, such as Agility (Demirkan \& Delen, 2013; Howe et al., 2008; Santaferraro, 2012), which is "often used to describe companies that are not able to adapt and to have a good performance in environments that change fast" (Overby, Bharadwaj, \& Sambamurthy. 2006, p. 120). Harris, Hevner, and Collins (2009) assessed Flexibility Capability based on the Dynamic Capability theory. They found that Flexibility can be even more necessary under initial uncertainty conditions, when it is necessary to have new types of controls, rather than just the traditional ones. Tallon and Pinsonneult (2011) assessed the moderating effect of Flexibility on companies' Agility. They worked with the concept of adaptability, which concerns the degree to which infrastructure can support different IT needs, as well as with the concept of scalability, which is based on the ability of IT to expand by adding or removing resources. The aim of this study is to analyze the effects of Flexibility Capability on organizational Agility based on proposition 4:

P4 - Higher Flexibility levels are related to higher organizational Agility levels.

\subsection{Reconfiguration Capability and Agility}

New technologies imply new competitive environments that require fast responses to changes in the environment, rather than just company reconfigurations. Reconfiguration also involves changes in the environment and the likelihood of engaging in resource re-combinations to enhance product-market adequacy (Wei \& Wang, 2010). According to Butler and Murphy (2008), reconfiguration refers to IT professionals' ability to adapt to and use new technologies to compete and, also, to adopt new routines. The model by Huang, Pan, and Zuo (2012) analyzes the process through which information management helps companies to act fast with relation to clients. They support the assumption that "information management capability is actually a fundamental capability that improves other organizational capabilities" (Mithas et al. 2011, p. 251). They show that companies must develop their Information Management Capability through a new reconfiguration of necessary resources and skills in order to achieve Agility. As with Flexibility Capability, one of the aims of this research was to find the positive effect of Reconfiguration Capability on organizational Agility. This gives rise to proposition 5:

P5 - Higher Reconfiguration Capability levels are related to higher organizational Agility levels.

\subsection{Agility and SCA}

The agility provided by new technologies and by the growing availability of data (Demirkan $\&$ Delen, 2013; Howe, et al., 2008) is expected to be affected by previously identified capabilities and to play an essential role in gaining Sustainable Competitive Advantages in this competitive environment. The influence of Agility on competitive advantages was already assessed by Roberts and Grover (2012, p. 232), who defined it as the organizational capability to achieve competitive advantages through competitive actions taken in changing and super-competitive environments. This impact of Agility was observed through the alignment between the ability to perceive and to respond.

In order to be a source of Sustainable Competitive Advantages, IMC must have a positive impact on the Agility Capability of responses to changes required by the context and influence Integration Capability and organizational Adaptation (Flexibility), as well as Reconfiguration Capability. Thus, the effect of Agility on the obtainment of Sustainable Competitive Advantages will be one of the assumptions assessed, as suggested in proposition 6:

P6 - Higher Agility levels are related to companies' Sustainable Competitive Advantages.

\subsection{Research model}

A model was suggested prior to the current research based on the propositions developed. The theoretical-conceptual model of the research is shown in Figure 1. It takes into account the theories adopted and the constructs identified. 
The model presented in Figure 1 depicts a research route (using the identified capabilities) for IMC to become a source of SCA. The dotted lines highlight two groups of capabilities, namely: IS capability (IMC and IS Integration Capability) and business capabilities (Integration, Flexibility, Reconfiguration, and Agility). The theoretical perspectives are represented by the elements in the background. The arrow that goes from IMC to SCA passes through the other capabilities that mediate this relationship, representing the basic theory, that is, the RBV and its extensions - Resource Complementarity (double arrow between IMC and Integration Capability) and Dynamic Capability (diamond-shaped balloon that relates the four capabilities identified in the literature). This model was previously qualitatively assessed through semi-structured interviews conducted with companies acknowledged for their excellence in information management and that occupy a leading position in their sectors. The content analysis of these interviews corroborated relationships observed in the literature and contributed to the definition of intermediate categories in the case study protocol.

\section{Methodological Procedures of Multiple Case Studies}

The framework proposed by Oliveira, Maçada, and Goldoni (2009) was used to carry out the following research strategy: planning, data collection, data analysis, results. Based on Yin (2010), this research can be described as explanatory, since it aims to confirm relationships and propositions in the previous research model. Multiple case studies (Benbasat, Goldstein, \& Mead, 1987; Lee, 1989) require the application of explanatory-type research. The goal was to identify evidence of causal relationships between the constructs analyzed based on the interaction between the two identified dimensions according to the qualitative analysis of the content collected in the companies assessed.

Figure 2 depicts each one of the research stages. The organizations were chosen based on different levels of information use. This was done in order to enrich the results by identifying maximum variations (Patton, 2002). The interviewees in the companies were chosen through the snowball technique (Biernacki \& Waldford, 1981), by taking into consideration the focus and process in each one of the companies. Their profile is summarized in Table 1.

As according to Yin (2010), the research protocol indicated the data collection project and research goals, model, and propositions. The protocol uses a table to list the constructs and their definitions, as well as their dimensions and references to the literature they come from. The initial protocol was analyzed by two experts (a $\mathrm{PhD}$ graduate and a PhD student) in case study research, who suggested changes to be assessed. The protocol was re-designed and submitted for analysis by four experts who were also as experienced as the aforementioned ones (two $\mathrm{PhD}$ graduates and two $\mathrm{PhD}$ students). Finally, the

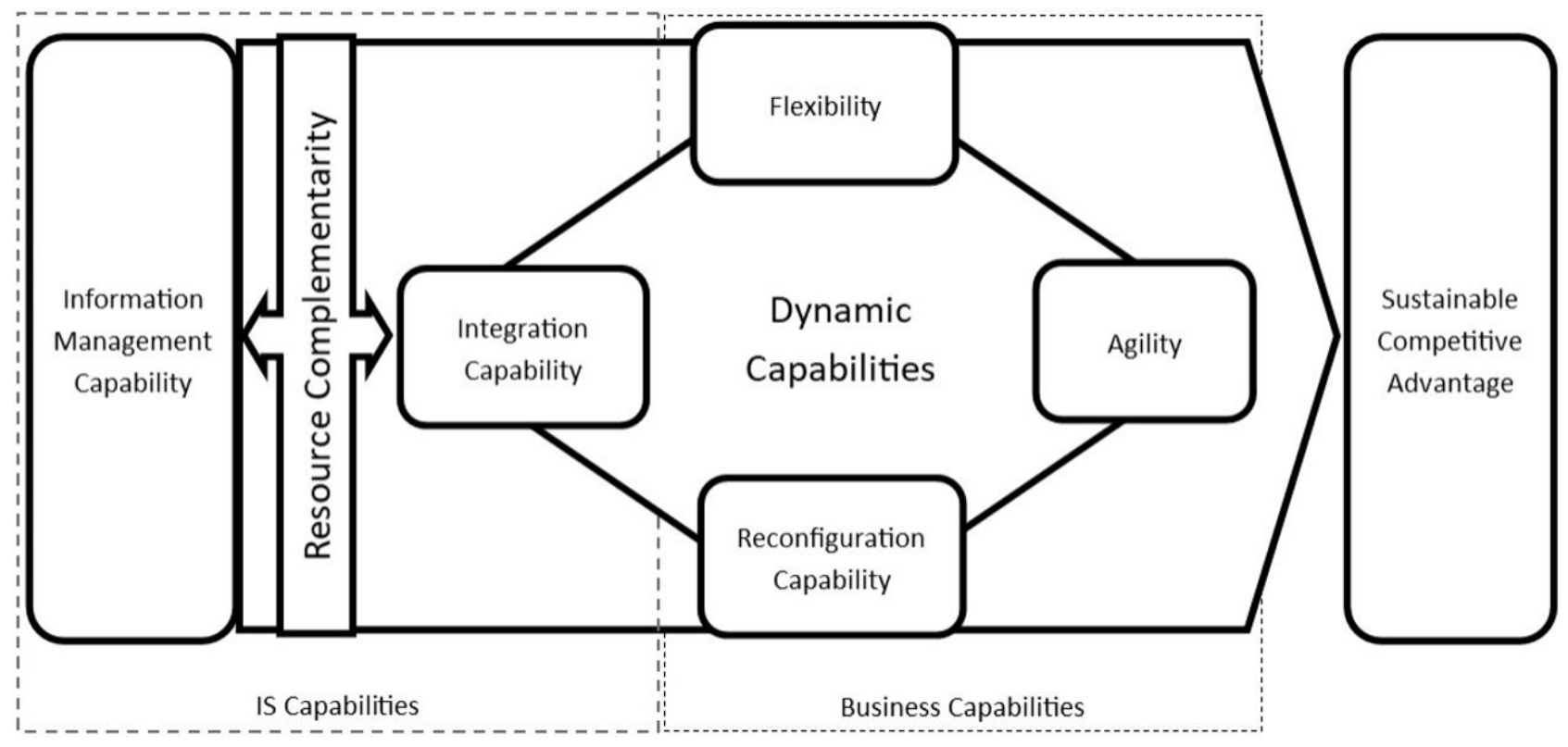

Figure 1. Theoretical-conceptual model of the research 


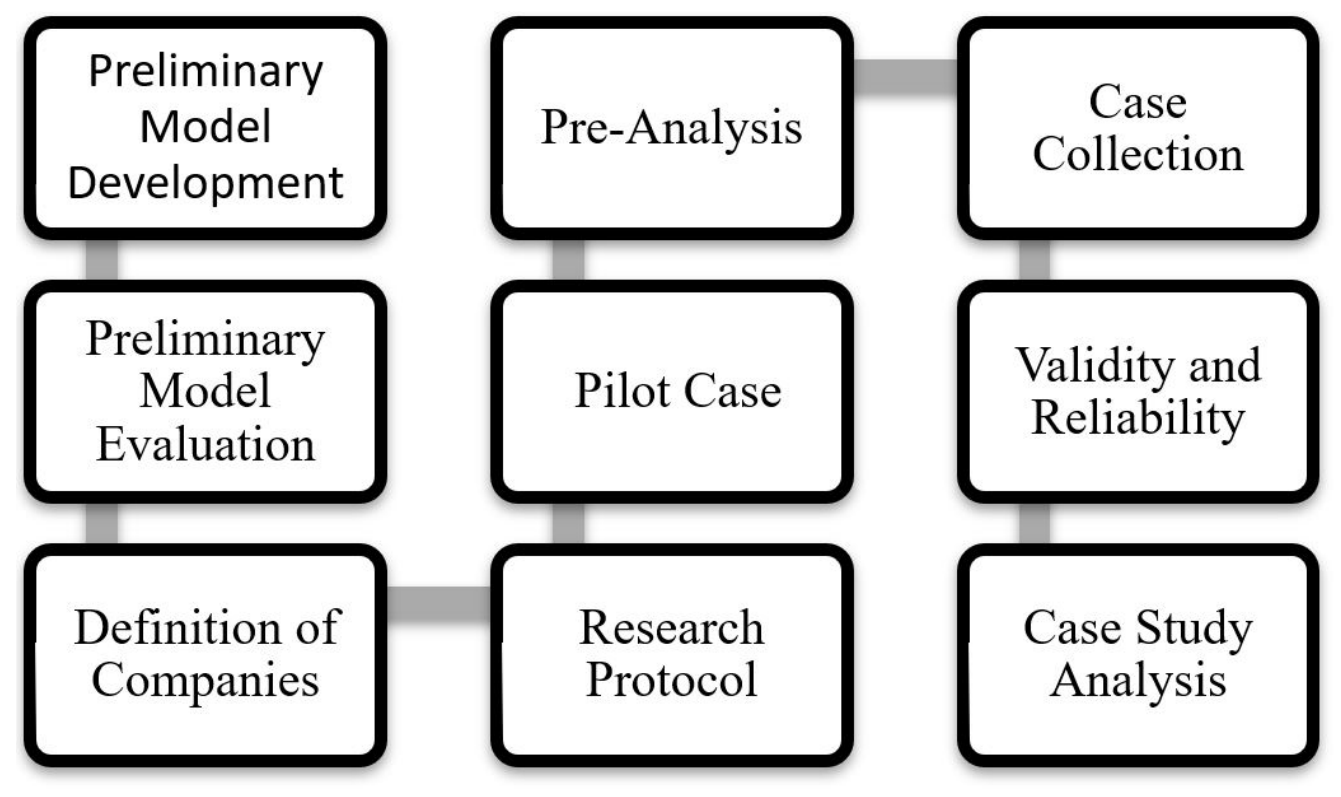

Figure 2. Research stages

Table 1.

\section{Interviewees' Profile}

\begin{tabular}{clccc}
\hline Interviewee & \multicolumn{1}{c}{ Function } & Time in that Function & Time in the Company & Field of Training \\
\hline CA1 & Core Banking Manager & 3 years & 8 years & IT \\
CA2 & BI and Business Modeling Manager & 9 years & 9 years & Management, Accounting \\
CA3 & BI Coordinator & 5 years & 7 years & IT, Management \\
CA4 & Business Unit Manager & 3.5 years & 8 years & Management \\
CA5 & Insurance Manager & 6 years & 11 years & Law, Management \\
CB1 & Head of E-commerce & 2 years & 5 years & Management \\
CB2 & Information Architecture Coordinator & 4 years & 9 years & IT \\
CB3 & E-commerce Coordinator & 1 year & 2 years & Management \\
CB4 & E-commerce Analyst & 1 year & 3 years & Management \\
CB5 & Marketing Manager & 2 years & 4 years & Communication \\
CC1 & IT Manager & 17 years & 17 years & IT, Management \\
CC2 & Information Management Analyst & 2 years & 30 years & Management \\
CC3 & Operations and IT Coordinator & 4 years & 15 years & IT, Management \\
CC4 & Integrated Systems Coordinator & 5 years & 13 years & Management \\
CC5 & Commercial Analyst & 2 years & 22 years & Management \\
\hline
\end{tabular}

final protocol presented questions in a semi-structured script. The final protocol (see Appendix A) was based on suggestions given by these experts. It was tested on Case A (pilot case) and incorporated into the multiple case study, since it was considered appropriate for the aims of the research.

In total, six companies were selected from different sectors, presenting different information uses.
The following three companies were selected from those that agreed to participate:

Case A (CA): a financial institution established by dozens of cooperatives supported by regional centers, which are members of a confederation, a foundation, and a cooperative database, besides other controlled companies. The company has 3 million associates, 1,400 service points, and 
$\mathrm{R} \$ 5$ billion in assets. It operates in 10 states of the Federation and has 20,000 employees. The research focused on processes related to Business Analytics (BA) and Business Intelligence (BI); Case $B(C B)$ : a retail chain, which is the national leader in its sector (350 stores). It operates in all Brazilian states. It is a public company that has 17,000 employees. It recorded $\mathrm{R} \$ 5.5$ billion in revenue in 2015. It is a market-leader, but is still consolidating its e-commerce sector. Thus, the e-commerce field was the first one subjected to the data collection procedure.

Case C (CC): a planned furniture manufacturer launched 75 years ago; it has national coverage. The company has 800 employees; it is the biggest furniture manufacturer in Latin America. A new department called Information Network Management was created in response to the difficulties in controlling the more than 250 exclusive sales representatives. This new department was the focus of our analysis.

In total, 16 interviews were conducted between July and December 2015; 896 minutes of recordings were transcribed, which resulted in 100,296 words. The data were codified in the MaxQDA software (version 11.1.2) for qualitative research. Appendix $\mathrm{C}$ shows examples of system outcomes, as well as the graphs used in the analysis applied for each proposition. Case A involved a search for news reports on the internet about the organization itself and documents provided by the company (flowcharts and reports). The interviewees in Case B did not present the internal documents of the company, but public documents on the company's website were assessed, for instance, the report on financial results. The interviewees in Case $\mathrm{C}$ showed IT management reports and reports on the company's Business Intelligence (BI) system organization. Moreover, internal documents and news reports available on the company's website were searched. Based on Bardin (2004) and Richardson (1999), the content analysis was carried out in three stages: pre-analysis; material analysis, and data treatment, inference, and interpretation.

Multiple data sources were used to validate the construct (Yin, 2010). As according to Eisenhardt and Graebner (1989), internal validity was achieved through the identification of consumption patterns between the compared units (crossing of interviewees in each case and between cases). Finally, reliability was accomplished through the use of the case study protocol (Oliveira et al.,
2009; Yin, 2010) and of the database developed in the support software.

According to Laville and Dionee (1999), there are three organizational category possibilities, namely: the open model (a posteriori categories), the closed model (a priori categories), and the mixed model (a mix of the other two categories). The closed model was used to assess cases whose categories were defined as a priori, based on the literature review presented in Chapter 3. Codification was carried out by two researchers and the divergent points were discussed by them. The categorization unit of the research was the topics addressed, i.e., "the signification unit that naturally unleashed itself from a text analyzed according to a certain criterion that concerns the theory that guides the literature" (Bardin, 2004, p. 99). The categorization criterion was semantic and took into account frequency as a counting rule, in other words, "a frequency measure in which all apparitions have the same weight" (Bardin, 2004, p. 102). However, this frequency was calculated from crossings of observations from the two final categories. A summary chart listing the results of each one of these categories is shown in Appendix B. Thus, the procedures described above also aimed to obtain 12 transparency and replicability criteria, as suggested by Aguinis and Solarino (2019).

\section{Case Analyses}

The pre-analysis stage allowed for a prior overview of the cases after the interviews were transcribed by a researcher. Taking into consideration that this is a flexible stage that allows adjustments in the goals and propositions, it was possible to observe the need to deal with the construct "IS Integration Capability" not as a single construct, but to analyze it as if it was two: Internal IS Integration Capability (IISIC), which concerns the integration of companies' internal systems; and External IS Integration Capability (EISIC), which also covers the integration of organizational systems through external organizational systems, for instance, regulating organs in Case A and retailers and suppliers in Case C. This process led to changes in the research propositions. The new research model is shown at the end of the section (Figure 3). The full analysis of the cases takes into account the new relationships that emerged. The summary charts listing the results of the analysis of each one of the sections are shown in Appendix B. 


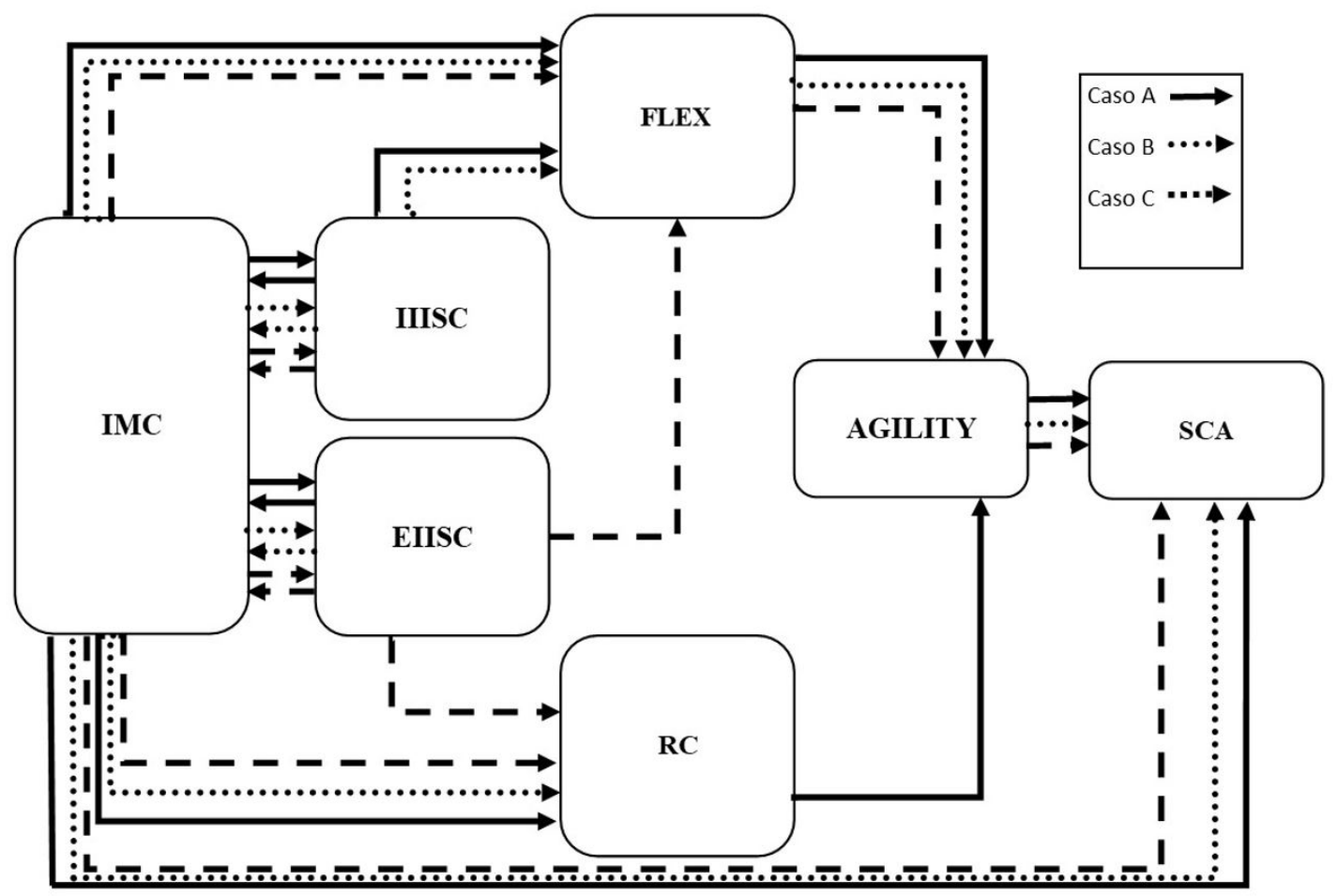

Figure 3. Compilation of Results per Case

\section{I Complementarity between IMC and Internal IS Integration Capability}

The analysis of Propositions 1a and $1 \mathrm{~b}$ aimed to understand the association between IMC and IISIC. The complementarity association between IMC and Internal IS Integration Capability was addressed in the literature (Graupner \& Mädche, 2012); however, it was not empirically tested. Complementarity implies the valorization of a resource, or capability, due to the presence of the other capability; this effect must happen simultaneously (Adegbesan, 2009; Taher, 2012).

Thus, the aim of this analysis was to reveal increased capability value due to the presence of the other capability. Cases whose intermediate dimension is deficient had a negative effect on the dimension of other capabilities.

Information infrastructure was the category that recorded the largest number of codifications among all cases ( 80 codifications). This codification was carried out 36 times in a paragraph that also had the codification of a certain dimension of IISIC. This paragraph shows a strong predecessor of the four intermediate categories (integrated access, integrated operations, sharing, and single input). These associations were identified in the three cases; thus, it is possible to infer that information infrastructure in the cases assessed is an important requirement to achieve an adequate level of Internal IS Integration.

Information distribution was the category that recorded the greatest occurrence of integrations with intermediate categories of IISIC; it recorded the best performance when it was preceded by these categories. This association was fully realized in Cases A and B; however, the relationship between distribution (IMC) and integrated access (IISIC) was not identified in Case A. Moreover, an inverse association was observed; distribution preceded the integrated operations of internal systems in this association.

Information architecture and integrated operations were associations that were not identified in any of the cases. However, when it comes to the other intermediate categories (integrated access, sharing, and single input), the architecture became a strong predecessor of integration at least in Cases A and B, since the only identification in Case $\mathrm{C}$ involved what preceded the single input. The 
integrated access in Case A was a requirement prior to the architecture.

Although access to information is one of the most codified categories in the cases, it did not present an association with the two intermediate categories of IISIC - integrated operations and access to information. This is likely to be because access to information requires information identification, perception, and collection in the environment. This collection is not necessary in environments where systems operate in an integrated way, since data are available - similar to information distribution. Similarly, observations of certain data which was already inserted - seem to be less relevant for the ability to perceive relevant data to be collected. On the other hand, access to information was a predecessor of integrated access in the three cases. It also preceded sharing in Cases A and B - the direction of the association with this category was reversed in Case C.

\subsection{Complementarity between IMC and External IS Integration Capability}

The analysis of Propositions 1a and $1 \mathrm{~b}$ aimed to understand the association between IMC and EISIC. External integration is more discussed in the IS literature than internal integration (Butler \& Murphy, 2008; Rai \& Tang, 2010; Roberts \& Grover, 2012); however, its association with IMC has not been assessed. The analysis of the results showed that the presence of IMC elements enhanced EISIC performance; the opposite was also true - there was no single direction in this association. Depending on the analyzed dimension, it can be found what preceded IMC (infrastructure and architecture) or intermediate categories of IMC (outspread and access) - this process resulted from intermediate categories of EISIC. However, the analysis based on EISIC showed that these directions were not very clear, since their intermediate categories were observed either before or after all intermediate categories of IMC. This outcome reinforced the complementarity association between these two capabilities.

The complementarity relationship between Information Management Capability and External IS Integration Capability was analyzed based on pathways between the two intermediate categories. The evidence regarding the influence of one capability instead of another were searched for and reported either when there was a positive influence because of its presence or negative due to its absence.
Information distribution - which also did not present an association with single input, as occurred with internal integration - presented the opposite direction in comparison to infrastructure. In other words, information distribution appeared to be more susceptible to impacts caused by intermediate categories of EISIC (integrated access, integrated operations, and sharing) and to have an impact on them. Again, the distribution of observations among the cases was greater in Case C. This direction was only observed in relation to sharing in Case $\mathrm{A}$, and to integrated access in Case B.

The relationship between information architecture and any of the intermediate categories of EIISIC was not observed in Case A. Cases B and C mostly presented a direction based on the infrastructure of the three intermediate categories of EIISIC (integrated access, sharing, and single input). With respect to integrated operations, the only evidence points in the opposite direction to the relationship, i.e., information architecture would experience a positive impact when the integrated operations of interorganizational systems were at adequate levels.

Finally, access to information was the consequence of the integration of well-developed external systems. This direction in Case A was only observed in the sharing relationship, but it also presented some evidence in Case C. The relationship with integrated access and integrated operations was identified in Cases B and C, and the relationship between access to information and input was not observed.

The analysis of the three cases shows that EISIC is more developed in Case C. This integration in Cases $\mathrm{A}$ and $\mathrm{B}$ was less intense, where it was often hard to identify the relationships between categories. With regard to information infrastructure, except for the single input category (which was not observed), all others (integrated access, integrated operations, and sharing) were the consequence of an adequate information infrastructure. This happened more often in Cases B and C; this direction was only observed in Case $\mathrm{C}$ in the relationship between infrastructure and external sharing.

Thus, it is possible to verify a complementarity relationship between IMC and EISIC if we analyze the evidence identified in the relationship between their intermediate categories. There were times when intermediate categories of IMC preceded EIISIC, such as in the case of infrastructure and architecture; on the other hand, there were cases when IMC was consequently influenced, for instance in the case of distribution and access. As 
for architecture, there was a dimension identified as a consequence when it was related to the integration of external systems operations. Therefore, IMC and EIISIC had a positive impact on each other depending on the dimension under analysis.

\section{$5 \cdot 3$ IMC and Flexibility}

The analysis of the proposition aimed to understand the relationship between IMC and Flexibility. The expectation that IMC would positively influence Flexibility was derived from indications in the literature, which has argued that Flexibility can be assisted by informational resources depending on how the company makes adjustments to comply with environmental changes (Golden \& Powell, 2000; Lee \& Xia, 2005). This influence has been observed in case studies based on the relationship between some intermediate categories of both capabilities.

The access to information dimension did not lead to any identification of the relationship with intermediate categories of Flexibility. This finding does not mean that evidence regarding links between them cannot emerge from the deepening of this relationship. Access to information is a skill required at the very beginning of the information management process, since organizational Flexibility is a skill that would benefit from already processed and distributed information. Hence, with regards to a sequence of stages, this distance may impair observations of the direct relationship. However, at some levels, the other intermediate categories of IMC were associated with Flexibility categories.

Information architecture was observed based on the three Flexibility categories: efficiency, versatility, and robustness. None of these were identified in Case $\mathrm{C}$, whose informational architecture is a concept established by the interviewees. It was not possible to observe this concept through the analysis of the documents accessed, so that observing their relationship was a hard task. Architecture in Case $\mathrm{C}$ was observed in relation to versatility; in Case $B$, it was related to efficiency and robustness.

With respect to information distribution, there was a relationship with efficiency, responsivity, and versatility. The link to the efficient adaptation of resources was the only relationship observed among these three cases. Versatility was related to information distribution in Case A and to responsivity in Case C. Accordingly, it is possible to make an association between efficiency and information distribution as a consequence of the relationship most often observed between pathways from IMC and intermediate categories of Flexibility.

Finally, Infrastructure was related to Flexibility in its two intermediate time dimension categories: efficiency and responsivity. Both relationships were identified in Case A, but adaptation speed in Case B was a factor that was sensitive to infrastructure, whereas efficiency to adapt to resources was observed in Case C. Thus, we can conclude that IMC has an influence on Flexibility - there is some evidence that this influence stands out in some relationships and that it is heterogeneously distributed between cases.

\subsection{IMC and Reconfiguration Capability}

The analysis of Proposition 3 aimed to understand the relationship between IMC and RC. Reconfiguration Capability is relevant when it is necessary to make a new configuration of organizational resources that correspond to a new competitive environment (Wei \& Wang, 2010). Although some relationships were not identified, there were a large number of positive pathways between intermediate categories of IMC and RC. All four IMC categories seemed to have an influence on at least two categories of each RC.

Access to information was the IMC dimension that affected the RC categories the most. Except for the combination of resources, all intermediate categories of $\mathrm{RC}$ seemed to be influenced by access to information. The association between access to information and adaptation to partners was observed in Cases B and C. The re-use of resources was affected by access to information in Case A. There was compatibility in Case $\mathrm{C}$, and this outcome reflects the likelihood of these companies being prone to adapt in order to gather relevant information about their partners.

Information architecture influenced adaptation to partners' patterns and to resource re-use. In the first case, this association was only observed in Case C, but the relationship with the re-use dimension was positive in Cases A and B. Information distribution was also associated with two intermediate categories of RC, namely: resource combination and adaptation. Both relationships were observed in Cases B and C.

Finally, information infrastructure was relevant for the three cases in relation to adaptation to new partners. Compatibility was another dimension affected by Infrastructure; however, this association was only 
seen in Case C. These two intermediate categories of RC (compatibility and adaptation) concern patterns between a company and its partners and market; they may adapt to their patterns to become compatible.

\subsection{Flexibility and Agility}

The analysis of Proposition 4 aimed to understand the relationship between Flexibility and Agility. Flexibility implies adaptation (Golden \& Powell, 2000). In order to respond to costumers, the company must often adapt in order to detect and perceive changes in the environment it operates in (Overby et al., 2006). There were pathways between the intermediate categories of these two capabilities. These observations were identified 48 times in 12 of the 16 pathways possible. The data analyzed in the pathways between Flexibility and intermediate categories of Agility indicated evidence of the precedence of Flexibility in relation to Agility. The distribution of these relationships between cases was heterogeneous.

\subsection{Reconfiguration Capability and Agility}

The analysis of Proposition 5 aimed to understand the relationship between RC and Agility. Agility is the capability to act in response to costumers and in the relationship with partners (Sambamurthy, Bharadwaj, \& Grover, 2003). The ability of a company to reconfigure resources in this field should help it to improve its agility. The influence of RC on Agility was perceived in some cases and between some categories; Case B, for example, only showed one association. In total, fewer than half of the possible pathways between capability categories showed any evidence. Based on some aspects, RC influences Agility in companies, although it is only verified in a few pathways. Taking into consideration the specificities of the cases assessed, mainly the low Reconfiguration Capability observed, it is not possible to generalize that this relationship is less important than the others.

\subsection{Agility and Sustainable Competitive Advantages}

The analysis of Proposition 6 aimed to understand the relationship between Agility and SCA. Increasing organizational agility is one of the ways to ensure higher competitiveness (Roberts \& Grover, 2012). Agility is influenced by Flexibility and RC, both boosted by IMC. Case studies have assessed the competitive potential to generate sustainable competitiveness based on the three requirements consolidated in the literature (Barney, 1991; Mata et al., 1995).

The potential to generate Sustainable Competitive Advantage was analyzed based on the pathways between its intermediate categories. Overall, there was good interaction with the categories in terms of influence, except for the heterogeneity pathway with adaption to the action plan.

Perception was the category among the intermediate categories of Agility that most influenced the three SCA categories. Besides identifying that perception can be an important mechanism to increase the strategic competitive potential of the company - since it has a positive association with the four SCA requirements - this influence was observed in most of the cases. The relationship between perception and immobility was identified in the three cases. On the other hand, the association with value was only identified in Cases B and C. Finally, the pathways with heterogeneity showed the influence of perception in Cases A and C.

Response was a category that also had many observed relationships. According to the analysis of the data collected from the cases, the way companies respond to changes in the environment is something that is valuable to them (Case A); it is distributed in a heterogeneous (Cases A and B) and perfectly motionless (Cases A, B, and C) way. Relationships with anticipation showed the same intensity. Value association was observed in Cases $\mathrm{A}$ and $\mathrm{B}$; Case $\mathrm{B}$ showed the influence of anticipation on heterogeneity. Finally, anticipation, in Case A, was related to immobility. Case $\mathrm{C}$ did not show any relationship for anticipation.

The potential of an action plan to adapt to SCA recorded the lowest identification. There was no relationship with heterogeneity. On the other hand, this adaptation was potentially valuable for the companies in Cases A and C. This category fulfilled the motionless requirement only in Case $\mathrm{C}$. Thus, although there were few relationships with action plan adaptation, the other intermediate categories of Agility (anticipation, perception, and response) were related to the companies' sustainable competitive potential.

\section{Discussion and Final Considerations}

Overall, the influence of IS resources and capability on company development tends to occur indirectly (Taher, 
2012; Wade \& Hulland, 2004). This does not mean the resources themselves, but the way these resources are generated and the skills that give competitive advantages to companies (Mata et al., 1995). Accordingly, the effects of Information Management Capability on company performance have been empirically supported as being indirect (Mithas et al., 2011). Integrated information delivery has a positive effect on the successful and effective use of information (Kettinger et al., 2013). Based on the need to develop a model to help represent the way IMC influences SCA, the aim was to find in the literature the constructs that could mediate this influence.

The relationships between categories were analyzed in-depth in order to better understand how they occur. This was done by evaluating pathways between elements and the dimensions of each capability. One of the results of the preliminary analysis in the pilot case derived from the need to disrupt Internal and External IS Integration Capabilities. The final analysis of the cases took into account this division, as well as the quantitative research. Some patterns related to propositions of the research model were identified in the cases: complementarity between SCA and Internal and External Integration Capabilities; the relationship between IMC and both Flexibility and Reconfiguration Capability; the relationship between Flexibility and Agility; and the relationship between Agility and SCA.

Figure 3 shows the relationships observed between capabilities in each one of the three cases. The differences observed between the cases helped to explain the occurrences seen in the proposed model. With respect to the complementarity between IMC and Integration Capabilities, the dotted line highlights the lowest-intensity direction in comparison to the opposite direction.

When it comes to the complementarity between IMC and IISIC, it is possible to observe that the most frequent relationship was observed from IISIC to IMC in Case C - unlike in the other ones. Similarly, the relationships from EISIC to Reconfiguration Capability and to Flexibility were observed in Case $\mathrm{C}$ - these did not occur in the other ones. Case $\mathrm{C}$ was the one that presented the highest level of external integration development. Thus, it can be understood that difficulties faced by the other two organizations in applying EISIC made it impossible to observe the positive effect of this capability on consequent skills, which ended up reinforcing the proposed relationships.
There were at least two ways through which IMC and Integration can influence companies's strategic performance. The most significant one was the path that goes from IMC to IISIC, which also had a positive impact on Flexibility - Agility was the intermediate element for competitive performance.

This study provides the following contributions to the IS literature: (a) it provides an answer to the controversy regarding the influence of IS resources and capability on companies' strategic development (Chae et al., 2014; Luse \& Mennecke, 2014; Wang et al., 2015), (b) it provides evidence about how IMC influences SCA - the natural dependent variable of SCA; (c) it provides evidence about the need to use organizational capabilities to mediate the influence of IS capabilities on strategic development; and (d) it perceives that internal and external integration capabilities must be observed as different categories, because they influence organizational capabilities in different ways. With respect to practical aspects, investments in information technologies have been growing by almost $12 \%$ a year (IDC, 2018). Taking into consideration the results in this study, managers should analyze aspects related to technology and Information Management Capability development in order to achieve the results expected from the investments made. Identifying different elements of IMC and how this skill - in combination with other capabilities - influences companies' competitiveness can help managers to make better decisions, based on the analysis of multiple variables. Showing the way these capabilities interact can help managers develop policies regarding investments in informational resources that lead to sustainable strategic gains. Information Management Capability is a practical concept that can show managers the need to understand that strategies with competitive potential must result from a set of skills developed based on informational resources, rather than just from isolated resources.

The nature of the companies selected is the limitation of this research. Although we were careful in choosing companies from different sectors that are leaders in their market (since the goal was to observe strategic performance), it is understood that the results cannot be extrapolated to other companies. Different methodological approaches might further contribute to the development of this topic in future studies. Quantitative studies could analyze the impact of the observed relationships. Qualitative approaches could be used to explore each one of these 
relationships in-depth or, also, an interventionist perspective could be applied to analyze aspects of the propositions.

\section{References}

Adegbesan, J. A. (2009). On the origins of competitive advantage: Strategic factor markets and heterogeneous resource complementarity. Academy of Management Review, 34(3), 463-475.

Aguinis, H., \& Solarino, A. M. (2019). Transparency and replicability in qualitative research: The case of interviews with elite informants. Strategic Management Journal, 40(8), 1291-1315.

Ali, M. S., \& Khan, S. (2019). Organizational capability readiness towards business intelligence implementation. International Journal of Business Intelligence Research (IJBIR), 10(1), 42-58.

Bardin, L. (2004). Análise de conteúdo (3a ed.). Lisboa: Ediçōes 70.

Barney, J. (1991). Firm resources and sustained competitive advantage. Journal of Management, 17(1), 99-120.

Benbasat, I., Goldstein, D. K., \& Mead, M. (1987). The case research strategy in studies of information systems. MIS Quarterly, 11(3), 369-386.

Bharadwaj, A. S., El Sawy, O. A., Pavlou, P. A., \& Venkatraman, N. (2013). Digital business strategy: Toward a next generation of insights. MIS Quarterly, 37(2), 471-482.

Biernacki, P., \& Waldorf, D. (1981). Snowball sampling: Problems and techniques of chain referral sampling. Sociological methods \& research, 10(2), 141-163.

Brinkhues, R., Freitas, J. C., Jr., \& Maçada, A. C. (2015). Information management capability as competitive imperfection in the strategic factor market of big data. Proceedings of the Twenty-First Americas Conference on Information Systems, Puerto Rico. Retrieved from https://aisel. aisnet.org/amcis2015/StrategicUse/GeneralPresentations/16/

Butler, T., \& Murphy, C. (2008). An exploratory study on IS capabilities and assets in a small-to-medium software enterprise. Journal of Information Technology, 23(4), 330-344.
Carmichael, F., Palacios-Marques, D., \& Gil-Pechuan, I. (2011). How to create information management capabilities through web 2.0. The Service Industries Journal, 31(10), 1613-1625.

Chae, H. C., Koh, C. E., \& Prybutok, V. R. (2014). Information technology capability and firm performance: Contradictory findings and their possible causes. MIS Quarterly, 38(1), 305-326.

Chen, H., Chiang, R. H., \& Storey, V. C. (2012). Business Intelligence and Analytics: From Big Data to Big Impact. MIS Quarterly, 36(4), 1165-1188.

Cochrane. (2018). Cochrane handbook for systematic reviews of interventions. Retrieved from http://www.cochrane.org/ training/cochrane-handbook/

Davenport, T. H., Barth, P., \& Bean, R. (2012). How ‘big data' is different. MIT Sloan Management Review, 54(1). Retrieved from https://www.hbs.edu/faculty/Publication $\% 20$ Files/SMR-How-Big-Data-Is-Different_782ad61f-8e5f4b1e-b79f-83f33c903455.pdf

Demirkan, H., \& Delen, D. (2013). Leveraging the capabilities of service-oriented decision support systems: Putting analytics and big data in cloud. Decision Support Systems, 55(1), 412-421.

Eisenhardt, K. M., \& Graebner, M. E. (2007). Theory building from cases: Opportunities and challenges. The Academy of Management Journal, 50(1), 25-32.

Gartner (2016). Big Data: What Information, if you had it, would change the way you run your business? Retrieved from http://www.gartner.com/technology/ topics/big-data.jsp/

Golden, W., \& Powell, P. (2000). Towards a definition of flexibility: In search of the Holy Grail? Omega, 28(4), 373-384.

Graupner, E., \& Mädche, A. (2012). Competitive advantage through process visibility-A Resource-based model. Working Paper Series in Information Systems, v. 5.

Grover, V., Chiang, R. H., Liang, T. P., \& Zhang, D. (2018). Creating strategic business value from big data analytics: A research framework. Journal of Management Information Systems, 35(2), 388-423. 
Harris, M. L., Hevner, A., \& Collins, R. W. (2009, August). Management of Software Product Development, Innovation and Adaptability. Proceedings of the Twenty-First Americas Conference on Information Systems, San Francisco, California, 274. Retrieved from https://aisel.aisnet.org/ cgi/viewcontent.cgi?article $=1246 \&$ context $=$ amcis 2009

Helfat, C., \& Peteraf, M. (2009). Understanding dynamic capabilities: Progress along a developmental path. Strategic Organization, 7(1), 91-102.

Huang, P. Y., Pan, S. L., \& Zuo, M. (2012). Being responsive to your customer: Developing customer agility through information management. International Conference on Information Systems, Orlando, FL, United State, 33. Retrieved from https://pdfs.semanticscholar.or g/8e41/9dafdbcb33546338eb73b6296e43bf95a18f.pdf

Howe, D., Costanzo, M., Fey, P., Gojobori, T., Hannick, L., Hide, W., ... \& Rhee SY. (2008). Big data: The future of biocuration. Nature, 455(7209), 47-50.

Kettinger, W. J., Zhang, C., \& Chang, K. C. (2013). Research note-A view from the top: integrated information delivery and effective information use from the senior executive's perspective. Information Systems Research, 24(3), 842-860.

Laville, C., \& Dionne, J. (1999) A construção do saber: Manual de metodologia da pesquisa em ciências humanas. Porto Alegre: Artmed.

Lee, A. S. (1989). A scientific methodology for MIS case studies. MIS Quarterly, 13(1), 33-50.

Lee, G., \& Xia, W. (2005). The ability of information systems development project teams to respond to business and technology changes: A study of flexibility measures. European Journal of Information Systems, 14(1), 75-92.

Levallet, N., \& Chan, Y.E. (2018). Role of digital capabilities in unleashing the power of managerial improvisation. MIS Quarterly Executive, 17(1), 1-21.

Luse, A., \& Mennecke, B. (2014). IT can matter: Coevolution fostering IT competitive advantage. Management Research Review, 37(6), 574-588.

Maçada, A. C. G., Brinkhues, R. A., \& Freitas, J. C., Jr. (2015). Big Data e as capacidades de gestão da informação.
ComCiência: Revista Eletrônica de Jornalismo Científico, (170). Retrieved from http://comciencia.br/comciencia/ handler.php?section $=8 \&$ edicao $=115 \&$ id $=1388$

Mata, F. J., Fuerst, W. L., \& Barney, J. B. (1995). Information technology and sustained competitive advantage: A resource-based analysis. MIS Quarterly, 19(4), 487-505.

McAfee, A., Brynjolfsson, E., Davenport, T. H., Patil, D. J., \& Barton, D. (2012). Big Data. The management revolution. Harvard Business Review, 90(10), 61-67.

Marchand, D. A., Kettinger, W. J., \& Rollins, J. D. (2000). Information orientation: People, technology and the bottom line. MIT Sloan Management Review, 42(3), 69-80.

Mikalef, P., Pappas, I. O., Krogstie, J., \& Giannakos, M. (2018). Big data analytics capabilities: A systematic literature review and research agenda. Information Systems and e-Business Management, 16(3), 547-578.

Mithas, S., Ramasubbu, N., \& Sambamurthy, V. (2011). How Information management capability influences firm performance. MIS Quarterly, 35(1), 237-256.

Patton, M. (2002). Qualitative research and evaluation methods (3rd ed.). London: Sage Publications.

Oliveira, M., Maçada, A. C. G., \& Goldoni, V. (2009). Forças e fraquezas na aplicação do estudo de caso na área de sistemas de informação. REGE: Revista de Gestão, 16(1), 33-49.

Overby, E., Bharadwaj, A., \& Sambamurthy, V. (2006). Enterprise agility and the enabling role of information technology. European Journal of Information Systems, 15(2), 120-131.

Rai, A., Patnayakuni, R., \& Seth, N. (2006). Firm performance impacts of digitally enabled supply chain integration capabilities. MIS Quarterly, 30(2), 225-246.

Rai, A., \& Tang, X. (2010). Leveraging IT capabilities and competitive process capabilities for the management of interorganizational relationship portfolios. Information Systems Research, 21(3), 516-542.

Roberts, N., \& Grover, V. (2012). Leveraging information technology infrastructure to facilitate a firm's customer 
agility and competitive activity: An empirical investigation. Journal of Management Information Systems, 28(4), 231-270.

Sambamurthy, V., Bharadwaj, A., \& Grover, V. (2003). Shaping agility through digital options: Reconceptualizing the role of information technology in contemporary firms. MIS Quarterly, 27(2), 237-263.

Sabherwal, R., \& Jeyaraj, A. (2015). Information technology impacts on firm performance: An extension of Kohli and Devaraj (2003). MIS Quarterly, 39(4), 809-836.

Santaferraro, J. (2012). Offloading Analytics. Business Intelligence Journal, 17(4), 43-48.

Shamim, S., Zeng, J., Shariq, S. M., \& Khan, Z. (2018). Role of big data management in enhancing big data decisionmaking capability and quality among Chinese firms: A dynamic capabilities view. Information \& Management. 56(6), 103135.

Taher, M. (2012). Resource-based view theory. In Y. R. Dwivedi., M. R. Wade., \& S. L. Schneberger (Eds.). Information systems theory: Explaining and predicting our digital society (Vol. 1, pp. 151-163). New York: Springer.
Tanriverdi, H., \& Uysal, V. B. (2011). Cross-business information technology integration and acquirer value creation in corporate mergers and acquisitions. Information Systems Research, 22(4), 703-720.

Tallon, P. P., \& Pinsonneault, A. (2011). Competing perspectives on the link between strategic information technology alignment and organizational agility: Insights from a mediation model. MIS Quarterly, 35(2), 463-486.

Teece, D. J., Pisano, G., \& Shuen, A. (1997). Dynamic capabilities and strategic management. Strategic management journal, 18(7), 509-533.

Wade, M., \& Hulland, J. (2004). Review: The resourcebased view and information systems research: Review, extension, and suggestions for future research. MIS Quarterly, 28(1), 107-142.

Wei, H. L., \& Wang, E. T. (2010). The strategic value of supply chain visibility: Increasing the ability to reconfigure. European Journal of Information Systems, 19(2), 238-249.

Yin, R. K. (2010). Estudo de caso: Planejamento e métodos. Porto Alegre: Bookman. 


\section{Appendix A - Case Study Protocol}

Data collection plan:

- Define the criterion to select the cases;

- Submit a request to possible companies;

- Send a new request to companies that have not replied within 7 days;

- Arrange the interview with the first interviewee (IS department);

- Gather overall information about the company of the case;

- Visit the company of the case;

- Conduct and record the interviews;

- Identify the interviewees;

- Notes about observations of directions;

- Collection of additional documents available and made available by the interviewee;

- Transcription of the interviews;

- Analysis of the material available: interviews, documents, and notes; and

- Write a report about the case study.

- Collection Sources

- Semi-structured interviews;

- Documents (publicly available and made available by the company); and

- Direct observation.

Case study instruments - Script of the semi-structured interview

Company data

- Company name:

- Sector:

- Year of foundation:

- Number of employees:

- Revenue in 2014:

- Contact name:

Interviewee data

- Interviewee's name:

- Time working in the company:

- Function:

- Time in that function:

- Academic training: 


\begin{tabular}{|c|c|c|c|}
\hline Construct & Definition & Dimensions & Reference \\
\hline \multirow{4}{*}{$\begin{array}{l}\text { Information } \\
\text { Management } \\
\text { Capability }\end{array}$} & \multirow{4}{*}{$\begin{array}{c}\text { Set of company skills that connect people and } \\
\text { information architecture, infrastructure, access, } \\
\text { and outspread in order to allow organizational } \\
\text { changes in response to the competitive } \\
\text { environment. }\end{array}$} & Access & Carmichael et al. 2011; Mithas et al. 2011 \\
\hline & & Infrastructure & Carmichael et al. 2011 \\
\hline & & Outspreading & $\begin{array}{l}\text { Carmichael et al. 2011; Mithas et al. 2011; } \\
\text { Pahdtare et al. } 2011\end{array}$ \\
\hline & & $\begin{array}{l}\text { Information } \\
\text { architecture }\end{array}$ & Carmichael et al. 2011; Mithas et al. 2011 \\
\hline \multirow{4}{*}{$\begin{array}{l}\text { Integration } \\
\text { Capability }\end{array}$} & \multirow{4}{*}{$\begin{array}{l}\text { Company capability achieved through the } \\
\text { implementation of the alignment process that } \\
\text { links systems, data, and internal processes (Rai } \\
\text { \& Tang, 2010; Roberts \& Grover, 2012). }\end{array}$} & Access & $\begin{array}{l}\text { Rai and Tang, 2010; Roberts and Grover, } \\
2008\end{array}$ \\
\hline & & Information Input & $\begin{array}{l}\text { Rai and Tang, 2010; Roberts and Grover, } \\
2008\end{array}$ \\
\hline & & Operations & Butler and Murphy, 2008 \\
\hline & & Sharing & $\begin{array}{l}\text { Rai and Tang, 2010; Roberts and Grover, } \\
\text { 2008, Butler and Murphy, } 2008\end{array}$ \\
\hline \multirow{3}{*}{ Flexibility } & \multirow{3}{*}{$\begin{array}{l}\text { Company capability concerning the degree } \\
\text { to which infrastructure can support different } \\
\text { needs (Tallon \& Pinsonneult, 2011). }\end{array}$} & Versatility & $\begin{array}{l}\text { Lee and Xia, 2005; Tallon and Pinsonneult, } \\
2011\end{array}$ \\
\hline & & Robustness & Tallon and Pinsonneult, 2011 \\
\hline & & Responsivity & $\begin{array}{l}\text { Lee and Xia, 2005; Tallon and Pinsonneult, } \\
2011\end{array}$ \\
\hline \multirow{4}{*}{$\begin{array}{l}\text { Reconfiguration } \\
\text { Capability }\end{array}$} & \multirow{4}{*}{$\begin{array}{l}\text { The capability to reconfigure a resource } \\
\text { quickly and efficiently in order to implement a } \\
\text { new configuration in accordance with the new } \\
\text { environment (Wei \& Wang, 2009). }\end{array}$} & $\begin{array}{l}\text { Adaptation to new } \\
\text { suppliers }\end{array}$ & Wei and Wang, 2009; Rai and Tang, 2010 \\
\hline & & $\begin{array}{l}\text { Combination of } \\
\text { new and existing } \\
\text { resources }\end{array}$ & Wei and Wang, 2009; Rai and Tang, 2010 \\
\hline & & $\begin{array}{c}\text { Market/supplier } \\
\text { compatibility }\end{array}$ & Wei and Wang, 2009 \\
\hline & & Re-use of assets & Rai and Tang, 2010 \\
\hline \multirow{4}{*}{ Agility } & \multirow{4}{*}{$\begin{array}{l}\text { Company capability to adapt and achieve good } \\
\text { performance in environments that change fast } \\
\text { (Overby et al., 2006). }\end{array}$} & $\begin{array}{c}\text { Perception regarding } \\
\text { changes }\end{array}$ & $\begin{array}{c}\text { Overby et al. 2006; Tallon and Pinsonneult, } \\
\text { 2011; Roberts and Grover, } 2012\end{array}$ \\
\hline & & Response to changes & $\begin{array}{c}\text { Overby et al. 2006;, 2011; Roberts and } \\
\text { Grover, 2012 }\end{array}$ \\
\hline & & Business adaptation & $\begin{array}{l}\text { Roberts and Grover, 2012; Tallon and } \\
\text { Pinsonneult, 2011 }\end{array}$ \\
\hline & & Anticipation & Roberts and Grover, 2012 \\
\hline \multirow{3}{*}{$\begin{array}{l}\text { Sustainable } \\
\text { Competitive } \\
\text { Advantages }\end{array}$} & \multirow{3}{*}{$\begin{array}{l}\text { This occurs when a strategy to create value - } \\
\text { that is not simultaneously implemented - is } \\
\text { implemented (Barney, 1991). }\end{array}$} & Value & $\begin{array}{l}\text { Barney, 1991; Mata et al. 1995; Nevo and } \\
\text { Wade, } 2010 .\end{array}$ \\
\hline & & Heterogeneity & $\begin{array}{l}\text { Barney, 1991; Mata et al. 1995; Nevo and } \\
\text { Wade, } 2010 .\end{array}$ \\
\hline & & Immobility & $\begin{array}{l}\text { Barney, 1991; Mata et al. 1995; Nevo and } \\
\text { Wade, } 2010 . \\
\end{array}$ \\
\hline
\end{tabular}

Questions script:

\begin{tabular}{|c|c|l|}
\hline \multirow{2}{*}{$\begin{array}{c}\text { Information } \\
\text { management } \\
\text { capability }\end{array}$} & Access to information & $\begin{array}{l}\text { 1) How does access to information about the internal and external environment } \\
\text { occur? }\end{array}$ \\
\cline { 2 - 3 } & Information architecture & $\begin{array}{l}\text { 2) How is it possible to map information to respond to business needs and } \\
\text { directions? }\end{array}$ \\
\cline { 2 - 3 } & Information outspread & $\begin{array}{l}\text { 3) How does the information outspread to employees, customers, and suppliers } \\
\text { occur? }\end{array}$ \\
\cline { 2 - 3 } & Infrastructure & $\begin{array}{l}\text { 4) How are adjustments in the systems and hardware done in order to meet } \\
\text { business needs and directions? }\end{array}$ \\
\hline Integration Capability & $\begin{array}{l}\text { 5) How does IT integration capability (access, information input, operations, } \\
\text { and sharing) help information management capability (information access, } \\
\text { infrastructure, outspreading, and architecture)? }\end{array}$ \\
\hline
\end{tabular}




\begin{tabular}{|c|c|l|}
\hline \multirow{5}{*}{ Integration capability } & Access & 6) How does the company integrate data about internal and external processes? \\
\cline { 2 - 3 } & Operations & 7) How do information exchange operations take place between different data? \\
\cline { 2 - 3 } & Input & $\begin{array}{l}\text { 8) How can the same data be recovered through different applications in the } \\
\text { company? }\end{array}$ \\
\cline { 2 - 4 } & Sharing & 9) How and with whom (internal and external) does the company share its data? \\
\hline IMC & $\begin{array}{l}\text { 10) How does information management (information access, infrastructure, } \\
\text { outspreading, and architecture) help IT integration capability (information access, } \\
\text { input, operations, and sharing) in the company? }\end{array}$ \\
\hline
\end{tabular}

\begin{tabular}{|c|c|l|}
\hline \multirow{2}{*}{ Robustness } & $\begin{array}{l}\text { 11) How does the company adapt, based on information, to unexpected changes } \\
\text { in the environment? }\end{array}$ \\
\cline { 2 - 3 } Flexibility & $\begin{array}{l}\text { 12) How does the company adapt, based on information, to expected changes in } \\
\text { the environment? }\end{array}$ \\
\cline { 2 - 3 } Versatility & $\begin{array}{l}\text { 13) How fast can the company respond, based on information, to changes in the } \\
\text { environment? }\end{array}$ \\
\cline { 2 - 4 } IMC & $\begin{array}{l}\text { 14) How does information management capability (information access, } \\
\text { outspread, and architecture) help company flexibility (robustness, versatility, and } \\
\text { responsivity)? }\end{array}$ \\
\cline { 2 - 3 } IT integration capability & $\begin{array}{l}\text { 15) How does integration capability (information access, outspread, and } \\
\text { architecture) improve company flexibility (robustness, versatility, and } \\
\text { responsivity)? }\end{array}$ \\
\hline
\end{tabular}

\begin{tabular}{|c|c|c|}
\hline \multirow{6}{*}{$\begin{array}{l}\text { Reconfiguration } \\
\text { Capability }\end{array}$} & Adapt to new suppliers & $\begin{array}{l}\text { 16) How does the company, based on information, reconfigure resources in the } \\
\text { supply chain in order to adapt to new suppliers? }\end{array}$ \\
\hline & Resource recombination & $\begin{array}{l}\text { 17) How does the company, based on information, combine existing resources to } \\
\text { meet changes in the environment? }\end{array}$ \\
\hline & Market compatibility & 18) How are standards applied by company employees accepted by the market? \\
\hline & Re-use & $\begin{array}{l}\text { 19) How does the company, based on information, re-use resources to better } \\
\text { meet market needs? }\end{array}$ \\
\hline & IMC & $\begin{array}{l}\text { 20) How does information management capability (information access, } \\
\text { infrastructure, outspread, and architecture) help the reconfiguration capability of } \\
\text { company resources (adaptation to new suppliers, resource combination, market } \\
\text { compatibility, and resource re-use)? }\end{array}$ \\
\hline & IT integration capability & $\begin{array}{l}\text { 21) How does IT integration capability (information access, input, operations, } \\
\text { and sharing) improve the company's resource reconfiguration capability } \\
\text { (adaptation to new suppliers, resource combination, market compatibility, and } \\
\text { resource re-use)? }\end{array}$ \\
\hline
\end{tabular}

\begin{tabular}{|c|c|c|}
\hline \multirow{8}{*}{ Agility } & Perception & $\begin{array}{l}\text { 22) How do mechanisms to monitor client trends and changes in competitors' } \\
\text { actions work? }\end{array}$ \\
\hline & Anticipation & 23) How does the company follow changes in the business environment? \\
\hline & Adaptation & $\begin{array}{l}\text { 24) How does the elaboration of a new strategic action in response to changes in } \\
\text { the business environment work? }\end{array}$ \\
\hline & Response & 25) How does the company respond to changes in the business environment? \\
\hline & IMC & $\begin{array}{l}\text { 26) How does information management capability (information access, } \\
\text { infrastructure, outspread, and architecture) improve company agility (perception, } \\
\text { anticipation, adaptation, and response)? }\end{array}$ \\
\hline & IT integration capability & $\begin{array}{l}\text { 27) How does IT integration capability (information access, infrastructure, } \\
\text { outspread, and architecture) improve company agility (perception, anticipation, } \\
\text { adaptation, and response)? }\end{array}$ \\
\hline & Flexibility & $\begin{array}{l}\text { 28) How does company flexibility (robustness, versatility, and responsivity) } \\
\text { improve company agility (perception, anticipation, adaptation, and response)? }\end{array}$ \\
\hline & Reconfiguration capability & $\begin{array}{l}\text { 29) How does reconfiguration capability (adaptation to new suppliers, resource } \\
\text { combination, market compatibility, and resource re-use) of company resources } \\
\text { improve company agility (perception, anticipation, adaptation, and response)? }\end{array}$ \\
\hline
\end{tabular}




\begin{tabular}{|c|c|c|}
\hline \multirow{7}{*}{$\begin{array}{l}\text { Sustainable } \\
\text { Competitive } \\
\text { Advantage }\end{array}$} & \multirow{2}{*}{ Value } & $\begin{array}{l}\text { 30) How does the information management capability (information access, infrastructure, } \\
\text { distribution, and architecture) add value to the company? }\end{array}$ \\
\hline & & $\begin{array}{l}\text { 31) How does the capability to perceive and respond (perception, anticipation, } \\
\text { adaptation, and response) to changes in the environment add value to the company? }\end{array}$ \\
\hline & \multirow[b]{2}{*}{ Heterogeneity } & $\begin{array}{l}\text { 32) How is it possible to identify differences in the performance of information } \\
\text { management strategies implemented between competitors? }\end{array}$ \\
\hline & & $\begin{array}{l}\text { 33) How can the capability to perceive and respond (perception, anticipation, adaptation, } \\
\text { and response) to changes in the environment help the company to become different from } \\
\text { its competitors? }\end{array}$ \\
\hline & \multirow{3}{*}{ Immobility } & $\begin{array}{l}\text { 34) How can the same information management resources be acquired by the } \\
\text { competitors? }\end{array}$ \\
\hline & & 35) How can the information management strategy be copied by the competitors? \\
\hline & & $\begin{array}{l}\text { 36) How can the capability to perceive and respond (perception, anticipation, adaptation, } \\
\text { and response) to changes in the environment impair the acquisition of the company's } \\
\text { strategic resources? }\end{array}$ \\
\hline
\end{tabular}

Data analysis technique

- Content analysis

Appendix B - Summary Chart of the Results

Chart $5.1-$

\section{Summary of the Case Analysis of the IMC/IISIC relationship}

\begin{tabular}{|c|c|c|c|c|c|}
\hline IISIC & Relationship & IMC & Case A & Case B & Case C \\
\hline Integrated Access & $\leftarrow$ & Infrastructure & $\leftarrow$ & $\leftarrow$ & $\leftarrow$ \\
\hline Integrated Access & $\rightarrow$ & Distribution & $\rightarrow$ & $\rightarrow$ & NI \\
\hline Integrated Access & $\leftrightarrow$ & Architecture & $\rightarrow$ & $\leftarrow$ & $\mathrm{NI}$ \\
\hline Integrated Access & $\rightarrow$ & Access & $\rightarrow$ & $\rightarrow$ & $\rightarrow$ \\
\hline Integrated Operations & $\leftarrow$ & Infrastructure & $\leftarrow$ & $\leftarrow$ & $\leftarrow$ \\
\hline Integrated Operations & $\leftrightarrow$ & Distribution & $\rightarrow$ & $\rightarrow$ & $\leftarrow$ \\
\hline Integrated Operations & NI & Architecture & NI & $\mathrm{NI}$ & $\mathrm{NI}$ \\
\hline Integrated Operations & $\mathrm{NI}$ & Access & $\mathrm{NI}$ & $\mathrm{NI}$ & $\mathrm{NI}$ \\
\hline Sharing & $\leftarrow$ & Infrastructure & $\leftarrow$ & $\leftarrow$ & $\leftarrow$ \\
\hline Sharing & $\rightarrow$ & Distribution & $\rightarrow$ & $\rightarrow$ & $\rightarrow$ \\
\hline Sharing & $\leftarrow$ & Architecture & $\leftarrow$ & $\leftarrow$ & $\mathrm{NI}$ \\
\hline Sharing & $\leftrightarrow$ & Access & $\rightarrow$ & $\rightarrow$ & $\leftarrow$ \\
\hline Single Input & $\leftarrow$ & Infrastructure & $\leftarrow$ & $\leftarrow$ & $\leftarrow$ \\
\hline Single Input & $\rightarrow$ & Distribution & $\rightarrow$ & $\mathrm{NI}$ & $\rightarrow$ \\
\hline Single Input & $\leftarrow$ & Architecture & $\leftarrow$ & $\mathrm{NI}$ & $\leftarrow$ \\
\hline Single Input & $\mathrm{NI}$ & Access & $\mathrm{NI}$ & $\mathrm{NI}$ & $\mathrm{NI}$ \\
\hline
\end{tabular}

Source: Elaborated by the authors 
Chart $5.2-$

\section{Summary of Case Analysis of the IMC/EIIS relationship}

\begin{tabular}{|c|c|c|c|c|c|}
\hline EIIS & Relationship & IMC & Case A & Case B & Case C \\
\hline Integrated Access & $\rightarrow$ & Access & NI & $\rightarrow$ & $\rightarrow$ \\
\hline Integrated Access & $\leftarrow$ & Architecture & $\leftarrow$ & $\leftarrow$ & NI \\
\hline Integrated Access & $\rightarrow$ & Distribution & NI & $\rightarrow$ & $\rightarrow$ \\
\hline Integrated Access & $\leftarrow$ & Infrastructure & $\mathrm{NI}$ & $\leftarrow$ & $\leftarrow$ \\
\hline Sharing & $\rightarrow$ & Access & $\rightarrow$ & NI & $\rightarrow$ \\
\hline Sharing & $\leftarrow$ & Architecture & NI & NI & $\leftarrow$ \\
\hline Sharing & $\rightarrow$ & Distribution & $\rightarrow$ & $\mathrm{NI}$ & $\rightarrow$ \\
\hline Sharing & $\leftarrow$ & Infrastructure & $\leftarrow$ & NI & $\leftarrow$ \\
\hline Single Input & NI & Access & $\mathrm{NI}$ & NI & $\mathrm{NI}$ \\
\hline Single Input & $\leftarrow$ & Architecture & NI & $\leftarrow$ & $\leftarrow$ \\
\hline Single Input & NI & Distribution & NI & NI & $\mathrm{NI}$ \\
\hline Single Input & NI & Infrastructure & NI & NI & NI \\
\hline Integrated Operations & $\rightarrow$ & Access & NI & $\rightarrow$ & $\rightarrow$ \\
\hline Integrated Operations & $\rightarrow$ & Architecture & $\mathrm{NI}$ & $\mathrm{NI}$ & $\rightarrow$ \\
\hline Integrated Operations & $\rightarrow$ & Distribution & NI & NI & $\rightarrow$ \\
\hline Integrated Operations & $\leftarrow$ & Infrastructure & NI & $\leftarrow$ & $\leftarrow$ \\
\hline
\end{tabular}

Source: Elaborated by the authors

Chart 5.3 -

\section{Summary of the Case Analysis of the IMC/Flexibility relationship}

\begin{tabular}{|c|c|c|c|c|c|}
\hline Flexibility & $\begin{array}{c}\text { Observed } \\
\text { Relationship }\end{array}$ & IMC & Case A & Case B & Case C \\
\hline Efficiency & YES & Infrastructure & YES & $\mathrm{NI}$ & YES \\
\hline Efficiency & YES & Distribution & YES & YES & YES \\
\hline Efficiency & YES & Architecture & $\mathrm{NI}$ & YES & $\mathrm{NI}$ \\
\hline Efficiency & YES & Access & $\mathrm{NI}$ & YES & YES \\
\hline Responsivity & YES & Infrastructure & YES & YES & NI \\
\hline Responsivity & YES & Distribution & $\mathrm{NI}$ & YES & $\mathrm{NI}$ \\
\hline Responsivity & $\mathrm{NI}$ & Architecture & $\mathrm{NI}$ & $\mathrm{NI}$ & $\mathrm{NI}$ \\
\hline Responsivity & YES & Access & $\mathrm{NI}$ & $\mathrm{NI}$ & YES \\
\hline Versatility & $\mathrm{NI}$ & Infrastructure & $\mathrm{NI}$ & $\mathrm{NI}$ & NI \\
\hline Versatility & YES & Distribution & YES & NI & $\mathrm{NI}$ \\
\hline Versatility & YES & Architecture & YES & $\mathrm{NI}$ & $\mathrm{NI}$ \\
\hline Versatility & $\mathrm{NI}$ & Access & $\mathrm{NI}$ & $\mathrm{NI}$ & $\mathrm{NI}$ \\
\hline Robustness & $\mathrm{NI}$ & Infrastructure & $\mathrm{NI}$ & $\mathrm{NI}$ & $\mathrm{NI}$ \\
\hline Robustness & $\mathrm{NI}$ & Distribution & NI & $\mathrm{NI}$ & $\mathrm{NI}$ \\
\hline Robustness & YES & Architecture & NI & YES & $\mathrm{NI}$ \\
\hline Robustness & $\mathrm{NI}$ & Access & $\mathrm{NI}$ & $\mathrm{NI}$ & $\mathrm{NI}$ \\
\hline
\end{tabular}

Source: Elaborated by the authors 
Chart $5.4-$

Summary of the Case Analysis of the IMC/RC relationship

\begin{tabular}{|c|c|c|c|c|c|}
\hline RC & $\begin{array}{c}\text { Observed } \\
\text { Relationship }\end{array}$ & IMC & Case A & Case B & Case C \\
\hline Compatibility & YES & Access & $\mathrm{NI}$ & NI & YES \\
\hline Compatibility & $\mathrm{NI}$ & Architecture & $\mathrm{NI}$ & $\mathrm{NI}$ & $\mathrm{NI}$ \\
\hline Compatibility & $\mathrm{NI}$ & Distribution & $\mathrm{NI}$ & $\mathrm{NI}$ & $\mathrm{NI}$ \\
\hline Compatibility & YES & Infrastructure & NI & NI & YES \\
\hline Re-use & YES & Access & YES & $\mathrm{NI}$ & NI \\
\hline Re-use & YES & Architecture & YES & YES & NI \\
\hline Re-use & $\mathrm{NI}$ & Distribution & $\mathrm{NI}$ & $\mathrm{NI}$ & $\mathrm{NI}$ \\
\hline Re-use & NI & Infrastructure & $\mathrm{NI}$ & NI & NI \\
\hline Combination & NI & Access & NI & NI & NI \\
\hline Combination & NI & Architecture & NI & NI & NI \\
\hline Combination & YES & Distribution & $\mathrm{NI}$ & YES & YES \\
\hline Combination & NI & Infrastructure & NI & NI & NI \\
\hline Adaptation & YES & Access & $\mathrm{NI}$ & YES & YES \\
\hline Adaptation & YES & Architecture & $\mathrm{NI}$ & NI & YES \\
\hline Adaptation & YES & Distribution & NI & YES & YES \\
\hline Adaptation & YES & Infrastructure & YES & YES & YES \\
\hline
\end{tabular}

Source: Elaborated by the authors

Chart $5.5-$

\section{Summary of Case Analysis of the Flexibility/Agility relationship}

\begin{tabular}{|c|c|c|c|c|c|}
\hline Agility & $\begin{array}{c}\text { Observed } \\
\text { Relationship }\end{array}$ & Flexibility & Case A & Case B & Case C \\
\hline Anticipation & $\mathrm{NI}$ & Efficiency & $\mathrm{NI}$ & $\mathrm{NI}$ & $\mathrm{NI}$ \\
\hline Anticipation & $\mathrm{NI}$ & Responsivity & $\mathrm{NI}$ & $\mathrm{NI}$ & $\mathrm{NI}$ \\
\hline Anticipation & YES & Robustness & NI & YES & $\mathrm{NI}$ \\
\hline Anticipation & YES & Versatility & YES & YES & YES \\
\hline Perception & YES & Efficiency & YES & NI & YES \\
\hline Perception & YES & Responsivity & YES & YES & YES \\
\hline Perception & YES & Robustness & YES & YES & NI \\
\hline Perception & YES & Versatility & NI & YES & NI \\
\hline Action Plan & $\mathrm{NI}$ & Efficiency & NI & NI & $\mathrm{NI}$ \\
\hline Action Plan & YES & Responsivity & YES & NI & YES \\
\hline Action Plan & NI & Robustness & NI & NI & NI \\
\hline Action Plan & YES & Versatility & YES & NI & NI \\
\hline Response & YES & Efficiency & YES & YES & YES \\
\hline Response & YES & Responsivity & YES & YES & YES \\
\hline Response & YES & Robustness & NI & NI & YES \\
\hline Response & YES & Versatility & YES & NI & NI \\
\hline
\end{tabular}

Source: Elaborated by the authors 
Chart $5.6-$

\section{Summary of the Case Analysis of the RC/Agility Relationship}

\begin{tabular}{|c|c|c|c|c|c|}
\hline Agility & Observed & RC & Casa A & Case B & Case C \\
\hline Anticipation & $\mathrm{NI}$ & Compatibility & $\mathrm{NI}$ & $\mathrm{NI}$ & $\mathrm{NI}$ \\
\hline Anticipation & $\mathrm{NI}$ & Re-use & $\mathrm{NI}$ & $\mathrm{NI}$ & $\mathrm{NI}$ \\
\hline Anticipation & YES & Combination & YES & $\mathrm{NI}$ & NI \\
\hline Anticipation & YES & Adaptation & NI & YES & NI \\
\hline Perception & YES & Compatibility & YES & $\mathrm{NI}$ & $\mathrm{NI}$ \\
\hline Perception & NI & Re-use & NI & $\mathrm{NI}$ & $\mathrm{NI}$ \\
\hline Perception & $\mathrm{NI}$ & Combination & $\mathrm{NI}$ & $\mathrm{NI}$ & $\mathrm{NI}$ \\
\hline Perception & YES & Adaptation & YES & NI & YES \\
\hline Action Plan & $\mathrm{NI}$ & Compatibility & $\mathrm{NI}$ & $\mathrm{NI}$ & $\mathrm{NI}$ \\
\hline Action Plan & $\mathrm{NI}$ & Re-use & NI & NI & NI \\
\hline Action Plan & NI & Combination & NI & NI & NI \\
\hline Action Plan & $\mathrm{NI}$ & Adaptation & $\mathrm{NI}$ & $\mathrm{NI}$ & $\mathrm{NI}$ \\
\hline Response & YES & Compatibility & $\mathrm{NI}$ & $\mathrm{NI}$ & YES \\
\hline Response & NI & Re-use & NI & NI & NI \\
\hline Response & YES & Combination & YES & NI & NI \\
\hline Response & YES & Adaptation & $\mathrm{NI}$ & NI & YES \\
\hline
\end{tabular}

Source: Elaborated by the authors

Chart 5.7 -

Summary of Case Analysis of the Agility/SCA Relationship

\begin{tabular}{|c|c|c|c|c|c|}
\hline SCA & $\begin{array}{c}\text { Observed } \\
\text { Relationship }\end{array}$ & Agility & Case A & Case B & Case C \\
\hline Value & YES & Anticipation & YES & YES & $\mathrm{NI}$ \\
\hline Value & YES & Perception & $\mathrm{NI}$ & YES & YES \\
\hline Value & YES & Action Plan & YES & NI & YES \\
\hline Value & YES & Response & YES & $\mathrm{NI}$ & $\mathrm{NI}$ \\
\hline Heterogeneity & YES & Anticipation & YES & NI & NI \\
\hline Heterogeneity & YES & Perception & YES & NI & YES \\
\hline Heterogeneity & NI & Action Plan & NI & NI & NI \\
\hline Heterogeneity & YES & Response & YES & YES & NI \\
\hline Immobility & YES & Anticipation & NI & YES & NI \\
\hline Immobility & YES & Perception & YES & YES & YES \\
\hline Immobility & YES & Action Plan & $\mathrm{NI}$ & NI & YES \\
\hline Immobility & YES & Response & YES & YES & YES \\
\hline
\end{tabular}

Source: Elaborated by the authors

Appendix C - Example of Output Table and CGI / IIIS Graphs

\begin{tabular}{|c|c|c|c|c|}
\hline & Agility/Anticipation & $\begin{array}{c}\text { AgilitylAction Plan } \\
\text { Adaptation }\end{array}$ & AgilitylResponse & AgilitylPerception \\
\hline Infrastructure & 8 & 8 & 24 & 33 \\
\hline Distribution & 4 & 3 & 29 & 21 \\
\hline Architecture & 10 & 8 & 24 & 17 \\
\hline Access & 12 & 13 & 16 & 29 \\
\hline
\end{tabular}

IMC / IIIS Graph 


\section{Supporting Agencies:}

Conselho Nacional de Desenvolvimento Científico e Tecnológico (CNPq) and Coordenação de Aperfeiçoamento de Pessoal de Nível Superior (CAPES).

\section{Authors:}

1. Antônio Carlos Gastaud Maçada, PhD in Business, Federal University of Rio Grande do Sul, Rio Grande do Sul, Brazil. E-mail: acgmacada@ea.ufrgs.br

ORCID

(1) 0000-0002-8849-0117

2. Rafael Alfonso Brinkhues, PhD in Business, Federal University of Rio Grande do Sul, Rio Grande do Sul, Brazil. E-mail: rafael.brinkhues@viamao.ifrs.edu.br

ORCID

(1) $0000-0002-9367-5829$

3. José Carlos da Silva Freitas Jr., PhD in Business, Federal University of Rio Grande do Sul, Rio Grande do Sul, Brazil. E-mail: josecf@unisinos.br

ORCID

(1) 0000-0002-9050-1460

\section{Contribuiçáo dos autores}

\begin{tabular}{|c|c|c|c|}
\hline Contribuiçáo & $\begin{array}{l}\text { Antônio } \\
\text { Maçada }\end{array}$ & $\begin{array}{c}\text { Rafael } \\
\text { Brinkhues }\end{array}$ & José Freitas Jr \\
\hline 1. Definiçâo do problema de pesquisa & $\sqrt{ }$ & $\sqrt{ }$ & \\
\hline 2. Desenvolvimento das hipóteses ou questóes de pesquisa (trabalhos empíricos) & $\sqrt{ }$ & $\sqrt{ }$ & $\sqrt{ }$ \\
\hline \multicolumn{4}{|l|}{ 3. Desenvolvimento das proposiçóes teóricas (ensaios teóricos) } \\
\hline 4. Fundamentação teórica/Revisão de Literatura & $\sqrt{ }$ & $\sqrt{ }$ & $\sqrt{ }$ \\
\hline 5. Definição dos procedimentos metodológicos & $\sqrt{ }$ & $\sqrt{ }$ & \\
\hline 6. Coleta de Dados & & $\sqrt{ }$ & $\sqrt{ }$ \\
\hline \multicolumn{4}{|l|}{ 7. Análise Estatística } \\
\hline 8. Análise e interpretação dos dados & & $\sqrt{ }$ & $\sqrt{ }$ \\
\hline 9. Revisão crítica do manuscrito & $\sqrt{ }$ & $\sqrt{ }$ & $\sqrt{ }$ \\
\hline 10. Redação do manuscrito & $\sqrt{ }$ & $\sqrt{ }$ & $\sqrt{ }$ \\
\hline 11. Outra (favor especificar) & & & \\
\hline
\end{tabular}

